San Jose State University

SJSU ScholarWorks

Faculty Publications, Information Systems \& Technology

$1-1-2011$

\title{
Effects of Perceiver / Target Gender and Social Networking Presence on Web-based Impression Formation
}

Timothy R. Hill

San Jose State University, timothy.hill@sjsu.edu

Leslie J. Albert

San Jose State University, leslie.albert@sjsu.edu

Shailaja Venkatsubramanyan

San Jose State University, shailaja.venkatsubramanyan@sjsu.edu

Follow this and additional works at: https://scholarworks.sjsu.edu/mis_pub

Part of the Management Information Systems Commons

\section{Recommended Citation}

Timothy R. Hill, Leslie J. Albert, and Shailaja Venkatsubramanyan. "Effects of Perceiver / Target Gender and Social Networking Presence on Web-based Impression Formation" International Journal of e-Politics (2011): 1-19. https://doi.org/10.4018/jep.2011040104

This Article is brought to you for free and open access by SJSU ScholarWorks. It has been accepted for inclusion in Faculty Publications, Information Systems \& Technology by an authorized administrator of SJSU ScholarWorks. For more information, please contact scholarworks@sjsu.edu. 


\section{INTERNATIONAL JOURNAL OF E-POLITICS}

April-June 2011, Vol. 2, No. 2

\section{Table of Contents}

\section{Research Articles}

1 Beautiful to Me: Identity, Disability, and Gender in Virtual Environments Abbe E. Forman, Temple University, USA

Paul M. A. Baker, Georgia Institute of Technology, USA

Jessica Pater, Georgia Institute of Technology, USA

Kel Smith, Anikto LLC, USA

18 Overcoming the Segregation/Stereotyping Dilemma: Computer Mediated Communication for Business Women and Professionals

Natalie Sappleton, Manchester Metropolitan University, UK

37 Would Elizabeth Cady Stanton Blog? Women Bloggers, Politics, and Political Participation

Antoinette Pole, Montclair State University, USA

55 Effects of Perceiver/Target Gender and Social Networking Presence on Web-Based Impression Formation

Leslie Jordan Albert, San Jose State University, USA

Timothy R. Hill, San Jose State University, USA

Shailaja Venkatsubramanyan, San Jose State University, USA

74 Gender, Power, and eDating

Celia Romm Livermore, Wayne State University, USA

Toni M. Somers, Wayne State University, USA

\section{INTERVIEW}

89 Empowering Youth Political Participation in Turkey: Interview with Itir Akdogan, University of Helsinki, Finland

Celia Romm Livermore, Wayne State University, USA

\section{BOoK Review}

95 Encyclopedia of Gender and Information Technology

Celia Romm Livermore, Wayne State University, USA 


\title{
Effects of Perceiver/Target Gender and Social Networking Presence on Web-Based Impression Formation
}

\author{
Leslie Jordan Albert, San Jose State University, USA \\ Timothy R. Hill, San Jose State University, USA
}

Shailaja Venkatsubramanyan, San Jose State University, USA

\begin{abstract}
As the Web has expanded in its use and utility it has fundamentally changed the way in which individuals gather and use information. This paper suggests that those changes give rise to tangible and significant effects in the impressions people form of others using Web-based information. This study explores the impacts of perceiver gender, target gender, and social networking presence on subjects 'perceptions of potential teammates otherwise unknown to them as revealed by ratings they assign based only on search engine results. Experiments reveal differences in how male and female perceivers view others'social networking activity in general and suggest that how the perceiver gender matches, or differs, from the gender of the target affects how social networking presence plays into impression formation. Findings hold implications for professionals, academics and individuals concerned with the role that Web-based information plays in impression formation and how inherent gender-based biases may affect power and politics in the workplace and beyond.
\end{abstract}

Keywords: $\quad$ ePerception, ePersona, Gender Differences, Impression Formation, Social Networking

\section{INTRODUCTION}

With growth in the use of computers and the Internet, we now live in a world where there are two spheres of existence-a physical sphere and a digital sphere. Many now rely on the Web as a reflection of reality for finding facts. For example, many turn to the Web to get the ad-

DOI: $10.4018 /$ jep.2011040104 dress of a store rather than consult traditional yellow pages in book form. This existential dichotomy between our physical and digital spheres of existence gives rise to a number of issues. One interesting issue is that people are able to perceive others and form opinions about them based solely on the information available about those people on the Web.

While it may be tempting to characterize the Web as essentially equivalent to traditional 
print media as a basis for forming impressions, a critical look reveals fundamental differences. For example, relative to traditional media, Webbased sources are easier to access, far more searchable, much more amenable to aggregation, and have a longer lifespan because of the refresh-ability afforded by their digital format. Further, these sources are growing exponentially with Web 2.0 technologies that allow anyone to create and post their own content. Kalyanaraman and Sundar (2008) suggest that today's Web-based sources and tools provide options for self-expression and self-presentation that are unprecedented. As the information paradigm changes, it follows that the processes, and thus outcomes, are being affected and it thus behooves us to explore them toward a better understanding and use.

One important aspect of the paradigm shift is that, ironically, though the self-publishing phenomenon enabled by the Web lacks the well-established integrity controls of traditional print media, it has become an important source of information for decision making in both personal and professional contexts. For example, a recent study sponsored by Microsoft surveyed 275 US hiring managers and human resource professionals about their hiring practices and found that $85 \%$ of these recruiters work for firms that have hiring policies requiring them to investigate potential candidates online and $70 \%$ admitted to turning down potential employees based on the information they found on the Web (Cross-tab Marketing Services, 2010). Given the importance of decisions being made based on impressions created solely from Web searches, it is imperative that we understand the characteristics of both the searcher and the searched that may impact formation of these impressions.

We examine this issue in greater detail using the concepts of ePersona and ePerception (Venkatsubramanyan \& Hill, 2007). ePersona refers to searchable digital information about a particular person from a variety of sources personal home pages, social and professional networking sites, organizational Web pages, news articles, blogs and others. ePerception is a term coined by Vazire and Gosling (2004) but was defined and further developed to refer to the perception formed by people about others depending primarily, if not exclusively, on the ePersona (Venkatsubramanyan \& Hill, 2007, 2009a, 2009b). Building upon their model of impression formation, we explore how the gender of the perceiver, and the presence or absence of social networking activity for an ePersona, affect the formation of an ePerception. Additionally we examine how these effects differ by the gender of the searched individual, the "target", as compared with that of the perceiver. The results are both interesting and valuable, particularly given the integral role gender issues play in the social power and political dynamic of the workplace as well as broader social contexts, because better understanding the inherent biases enables awareness that can empower the affected individuals.

The paper is organized as follows. First we describe the theoretical background, present Venkatsubramanyan and Hill's (2009b) model of Web-based impression formation, develop our research question and put forward the propositions used to guide our research. Next we describe the experimental methodology for an empirical study designed to address the research question, followed by a discussion of results and their interpretation. We conclude with a summary and a discussion of the study's limitations, implications and directions for future research.

\section{THEORETICAL DEVELOPMENT}

In existing models of impression formation, the perceiver is the person forming an impression, while the target is the person about whom the impression is formed. People form impressions about others based on primary (or direct) and secondary (or indirect) sources of information. Primary sources of information include personal interactions (face-to-face or otherwise) including both verbal and behavioral cues. Secondary sources of information include sources such as hearsay (opinions expressed by others), photo- 
graphs, voice recordings, official records, news articles, biographies, and others, now including Web-based information.

Traditional models are grouped into two main categories: trait-based and stereotypebased. In the trait-based models, such as Asch's Configural Model and Anderson's weightedaverage model, various traits of the target come together in the perceiver's mind to form a unified impression (Brewer, 1988). According to Asch, there are two types of traits-central traits (traits that have a strong effect on interpretation of other traits) and peripheral traits (traits that do not significantly affect subjects' impressions of the perceived personality). Other researchers have found a primacy effect where traits that appear first have more impact in final impression (Widmeyer \& Loy, 1988). On the other hand, stereotype-based models theorize that people rely on social categories, or stereotypes, to form impressions since stereotyping reduces the amount of information to which perceivers must attend. Using a stereotype, a perceiver may infer the person's personality attributes without having to attend carefully to that person's behavior (Sherman, Lee, Bessenoff, \& Frost, 1998).

These existing perception models provide the foundation for a model of Web-based perception that recognizes the Web as a new medium that "changes the game." The uniqueness of the Web as a source of information and medium of communication can be seen in emerging studies of impression formation in the digital age (Hancock, 2001; Jacobson, 1999; Markey \& Wells, 2002; Walther, 1997; McKenna \& Bargh, 2000). Venkatsubramanyan \& Hill (2007) describes this model of ePerception (Figure 1) that extends traditional models of perception to account for differences effectuated by the digital information domain, specifically, by the way Web-based search impacts our perceptions of others.

As shown in the figure, there is a perceiver and a target as in traditional perception models (Brewer, 1988). The characteristics of both the perceiver and the target feed into a traditional impression formation process. In the digital domain, perceiver characteristics go beyond traditional notions of personality, emotional state, and social characteristics to include factors such as level of information literacy, online experience and comfort level, and search skill expertise. For instance, a study conducted by Ford, Miller, and Moss (2005) concluded that cognitive styles, levels of prior Internet experience and perceptions, study approaches, age and gender affect retrieval effectiveness. As in face-to-face contexts, existing stereotypes may also influence perceivers though some research suggests that this influence differs in the digital sphere too (Lee, 2004).

The target and the ePersona are shown as separate entities since the ePersona may also be affected by factors beyond the characteristics, behavior and control of the target such as the perceived currency and aesthetic of information sources, links between pages, and production quality of the information (e.g. picture clarity of images or videos).

The searchability effect refers to the impact of the search process itself (apart from the results) on the impression being formed (and subsequently the decision being made). Filtering search results then plays into searchability as cognitive effort is theorized to impact the impression formation process and outcome. Perusing the search results themselves then impacts the process through the target information, influenced by the characteristics of the information sources themselves. The perceiver considers all these factors to finally form an impression of the target, which then flows into the decision making process (such as hiring the target for a prospective employment position).

The theoretical model (Figure 1) provides a framework for empirical investigation of the impact of the Web on impression formation. The central research questions raised by this model are - (a) How do characteristics of Web-based search results impact impression formation? (b) How does the search process, by itself, affect impression formation? (c) How do the characteristics and skills of perceivers influence their perceptions of ePersonas? and (d) What characteristics of targets are most influential 
Figure 1. Web-based perception model: ePersona and eParticipation

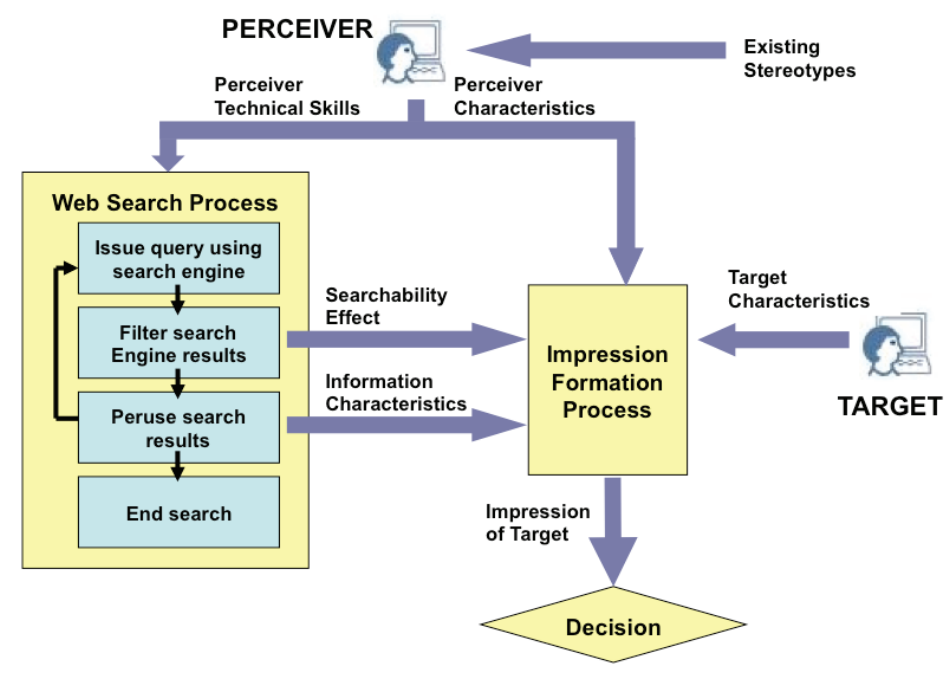

in the creation of an ePersona and perceivers' impressions of that ePersona? Our study of the literature revealed that the first question is currently being studied in some quarters (Vazire \& Gosling, 2004). Studies related to the remaining questions, however, are lacking in current literature. In this study, we investigate the roles of perceiver and target characteristics, specifically gender and social networking presence, in the formation of ePerceptions.

Our research question is thus: How do differences in perceiver gender and target gender affect the impressions formed based upon an ePersona's social networking activity?

\section{PERCEIVER AND TARGET CHARACTERISTICS: GENDER}

As seen in Figure 1, the proposed model of Webbased perception suggests that the individual characteristics of both the perceiver and the target play an important role in the impression formation process. Although there are many characteristics of interest, we chose to focus this study on the effects of perceiver and target gender for two main reasons. First, studies such as Gefen and Straub (1997) suggest that men and women may perceive and use communication technologies, such as email, differently. One explanation of these differences is that women may perceive a higher degree of social presence in online contexts, as Richardson and Swan (2003) found in their study of online courses. Females may also perceive online information sources differently than males. For example, Huffaker and Calvert (2005) analyzed gender identity and language issues based on entries in the Web 2.0 online journal phenomenon "blogs" (Web logs) and found this new media format surfaced gender-based differences that broke from stereotypical expectations. Venkatsubramanyan and Hill (2009b) found that women's decision making processes may be more influenced by a potential teammate's social networking activity than are men's suggesting that perceiver gender may contribute to differences in ePerceptions.

Second, gender stereotypes may also influence impression formation. Computer mediated communication (CMC) has been shown to reduce the available amount of "individuating information," cues that allows us to differentiate between group members (Lee, 2004). Although one might expect gender to play less of a role when social cues are limited, research suggests differently (Lea \& Spears, 1991). The Social Identity model of Deindividuation 
Effects (SIDE) suggests that group members with insufficient individuating information for forming perceptions will fill the void by assigning stereotypical traits to other members of their group. SIDE also suggests that a lack of individuating information about others leads to a greater affinity with one's own group (i.e. those of the same gender, race, nationality, etc.) and a greater likelihood that one will exhibit the stereotypical behaviors attributed to that group (Postmes \& Spears, 2002). This is particularly relevant to the formation of ePerceptions as Web-based searches do not allow targets to provide supplemental individuating information and thus gender stereotypes and gender affinity may play a greater role in the formation of ePerceptions than they would in impressions formed face-to-face. Further, research also suggests that gender stereotype effects are so powerful that even minimal gender cues can encourage the assignment of gender stereotypes to others. Lee (2004) found that gendered cartoon avatars alone were sufficient for individuals to assign stereotypical behaviors and attributes to group mates in CMC contexts even when those individuals were told that the gender of the avatar may or may not match the actual gender of the group mate. Similarly, Nass, Moon, and Green (1997) found that subjects assigned gender stereotypes to computers that exhibited male and female voices and responded accordingly. These studies all suggest the importance of both perceiver and target gender in the formation of ePerceptions.

\section{ePersona Characteristics: Social Networking Activity}

As with individual characteristics of the perceiver and target, we suggest that characteristics of a target's ePersona also impact perceivers'impressions of the target. The ePersona includes all digital information that maybe gathered about an individual via a search engine. This information may be generated by the target, such as personal Web pages and blog entries, or by third parties, as in the case of news articles, public records and others' Web posting about the target. In this study, the ePersona aspect on which we focus is social networking, due to its popularity among participants (Facebook alone claims to have over 200 million users as of 2009) and among organizations looking to vet potential employees (CareerBuilder, 2008) as well as literature, cited above, indicating that gender and social networking effects may be interrelated.

Beyond their wide acceptance, social networking sites also offer unique information about individual targets. Unlike personal Web pages, which consist primarily of targetcontrolled information, social networking sites combine target and third party-generated information about target individuals. According to Warranting Theory (Walther \& Parks, 2002), perceivers value others' opinions and views of an individual over that individual's self-evaluation. Applying Warranting Theory to ePerception suggests that the key role that third party-generated content plays in social networking, in the form of friends' comments, for example, would render those sites more salient to the impression formation process than target-controlled sites and indeed Walther, Van Der Heide, Hamel, and Shulman (2009) found this to be true. Futhermore, Back, Stopfer, Vazire, Gaddis, Schmukle, Egloff, and Gosling (2010) suggests that it is difficult for individuals to misrepresent themselves on social networking sites as any attempts to do so may be viewed and corrected by others and thus social networking sites are perceived as more accurately representating target individuals, a fact that may further increase the impact of social networking activity on Web-based impression formation. Lastly, their own gender may be expected to affect the way perceivers view social networking participation as suggested by Walther, Van Der Heide, Kim, Westerman, and Tong (2008) in a study that analyzed reactions to both the comments and attractiveness of friends in Facebook and found males and females differently impressed.

Combining these prior studies with the theoretical model presented in Figure 1, we begin our investigation of the roles of gender and social networking activity in ePerception 
with a set of propositions to be assessed experimentally. Propositions, rather than hypotheses, are presented here as overarching conceptual statements, each representing a series of testable statements too numerous to list individually.

First we draw from Warranting Theory to propose that social networking engagement, in and of itself, implies a willingness to be perceived through more credible third-party sources of information and this extends naturally to a range of positive associations, so perceivers of both genders will tend to view ePersonas with social networking more favorably than those without:

P1a. Males will perceive a target ePersona with social networking presence more positively than a target ePersona without social networking presence.

P1b. Females will perceive a target ePersona with social networking presence more positively than a target ePersona without social networking presence.

We then build upon the literature on perception differences between genders to propose that both males and females will assign gender stereotypes to gendered ePersonas and express greater affinity with their own gender group in low-cueing CMC contexts such as search engine results.

P2a. Females will perceive a female target ePersona without social networking presence more positively than a male target ePersona without social networking presence.

P2b. Females will perceive a female target ePersona with social networking presence more positively than a male target ePersona with social networking presence.

P2c. Males will perceive a male targetePersona without social networking presence more positively than a female target ePersona without social networking presence.

P2d. Males will perceive a male targete Persona with social networking presence more positively than a female target ePersona with social networking presence.
Based upon prior studies that suggest gender differences in interactions with, and perceptions of, CMC and upon recognized gender-stereotypical responses, we further propose an interaction effect between social networking activity and target gender that will differ for female and male perceivers.

P3a. Females will perceive the value of social networking differently for male targets than for female targets.

P3b. Males will perceive the value of social networking differently for female targets than for male targets.

\section{EXPERIMENTAL METHODOLOGY}

In this study we use personality dimensions as developed in Venkatsubramanyan and Hill (2007) to assess the perceiver's impression of a target ePersona as a potential project teammate. Venkatsubramanyan and Hill(2007) began with the traditional five-factor model of personality traits (Watson, 1989). The five-factor model comprises a hierarchical organization of five basic personality dimensions: Extraversion, Agreeableness, Conscientiousness, Neuroticism, and Openness to Experience. These five basic factors break down further into 106 personality dimensions. Through pilot testing the authors reduced the original personality dimension list down to a set of nine dimensions deemed by subjects as the most applicable for assessing potential teammates based solely on Web-based perceptions. These include (a) Commitment to Excellence, (b) ability to work as an Effective Team Member, (c) ability to Manage Multiple Tasks, (d) ability to Handle Conflict, (e) having a strong interest in Working with People, (f) Managing Anger, (g) ability to Take Direction, (h) Curiosity, and (i) ability to Adapt to New Situations. The current study employs these same personality dimensions to assess perceivers' impressions of ePersonas.

Our experimental design used university students to evaluate ePersonas for the purpose 
of selecting potential team members for a class project. Subjects were recruited from several upper division undergraduate business courses and offered course credit for their participation. 210 participated in the study including 104 males and 106 females and a wide range of business specialties (Finance, Management, etc.). The task of selecting and evaluating a potential teammate was chosen for two main reasons. First, most college students have experience working in teams on course projects, and in many cases had to select those teammates themselves, thus the task was an appropriate one for our subjects. Second, we suggest that the process of vetting potential teammates parallels the decision making processes required to assess and select one or more individuals from a pool of candidates and that these processes are largely independent of context. Examples of such decisions include selecting members for work-based teams, creating a short list of candidates for job interviews and choosing among professional service providers. The specific task of selecting a potential teammate is merely the scenario we used to develop a better understanding of how we form impressions of others based upon Web searches and we suggest that this scenario does not greatly limit the generalizability of our findings.

The experiment was conducted online with each subject randomly assigned to one of four manipulations representing the different potential teammates: John Doe 1, John Doe 2, Jane Doe 1 and Jane Doe 2. Each subject was provided a list of Google-style search results pertaining to his or her assigned potential teammate ePersona and was informed that the individual's name had been changed to preserve anonymity. The search result links were disabled so that subjects' information regarding the potential teammate was limited to the search results lists alone. If any link was clicked upon by the subject, a pop up message saying "DNS server is down. Please try again later." was generated. Search results for John Doe 1 and Jane Doe 1 each contained 10 results, 8 of which were links to social networking sites.
The results lists for John Doe 2 and Jane Doe 2 also contained 10 links though none of the results for these two ePersonas were to social networking sites. Please see Appendices A and B for screen captures of the search results for Jane Doe 1 and Jane Doe 2.

After looking at the search results page, subjects were asked to report the number of minutes spent reviewing the results to get an estimate of the amount of cognitive effort exerted in assessing the ePersona. Subjects were then asked to score the target as a potential team member on the nine factors described above. A five point Likert scale ranging from "-2" (very unfavorable impression) to " +2 " (very favorable impression) was used for each of these factors (Likert, 1932). Additionally, subjects were asked to rate the desirability of the target as a potential team member and their confidence in these desirability ratings. Also included in the rating was the question:

\section{"Ifyou are forced to make a decision at this point with no further information, would you select this person to be on your team - yes or no?"}

Answers to this yes or no question were coded in the form of 1 or 0 for analysis purposes. On a scale of 1 to 5 , subjects were asked to indicate how confident they felt about their decision. Subjects were asked to provide qualitative feedback as answers to these two questions:

(a) What kind of teammate would the student be?

(b) What do you think influenced your decision?

Demographic information was also collected about the subjects including factors such as age, gender, major, number of team projects performed in the past, number of computer related courses, number of years of computer experience, number of years of experience searching the Internet, frequency of Web search, and a self-rating of his or her own level of Web search skills. 


\section{ANALYSIS AND DISCUSSION}

To begin the data analysis, the qualitative, open-ended responses were reviewed to confirm that the subjects were sufficiently engaged in the scenario and to identify any notable trends. Several observations surfaced:

1. Nearly all subjects responded with written feedback and in every case the message was sensible and earnest, showing an investment in the scenario that lends veracity and credibility to the results, e.g.

"Due to John Doe's Web presence, Ifeel that he would be a good team member since he seems to have the desire to be connected with friends and associates. Having a LinkedIn, account shows that he has contacts that have worked or are working in business environment. Plus, itseems that he has also created a Website for himself, which shows that he is technically savvy."

2. A small but noticeable minority of respondents expressed frustration that there was not enough information for them to feel comfortable with the decision (mostly for the ePersonas with no social networking presence) but this reinforces that they were invested in the scenario and reminds us that we are studying first impressions that don't always lead to outcomes in and of themselves, e.g.

"There is nothing to assure that she is a good candidate for the team; therefore it would not be wise to base the decision on the information shown in the Google search results."

3. Overwhelmingly, respondents did attend to social networking presence strongly and extrapolated that to various trait implications, including those associated with the teammate decision, e.g.

"The search results show that he has strong social network connections. Therefore, he should be an active, sociable and energetic person. He seems to be teammate-material."

4. A number of respondents derived surprisingly broad and strong negative character traits from the ePersonas that were essentially neutral, merely lacking social networking presence, e.g.

"Not outgoing, unsocial, shy, quiet, and keeps to himself."

"The fact that there's almost nothing out there abouther... She seems like she probablydoesn't have much ambition or desire to do anything or accomplish anything."

"Not social from the fact he doesn't use any SNS which is very strange these days."

This suggests that at least some social networking presence may now be considered the norm with deviations leading to negative associations.

5. It was clear that in addition to the negative associations of too little social networking presence, there is a recognition that too much may be bad, at least in the project/ teammate scenario, e.g.

"The fact that she is on most of the social networks. I would want her on the team because of her people skills that she could possibly have; however, it makes me worry that she would spend too much time online rather than working on the project."

"Jane doe would be a slacker. All of the pages described for this potential team mate were social sites, she would probably get distracted easily and not be focused on getting work done."

Based on the qualitative analysis then, it is clear that the data is reliable and reflects the intended manipulations. Further, the apparent 
strength of impact underscores the value of the research. In addition, the expectation of social networking presence and the sensitivity to the level or degree to which it appears in an ePersona raise unforeseen issues informed by this study but needing further research.

The quantitative data were analyzed with respect to the research model and propositions, yielding additional insights from both expected and unexpected results. Standard statistical significance tests were applied for comparison of group mean pairs corresponding to the propositional statements.

The results are summarized in tables that list the experimental measures as rows and the various treatment group comparisons in columns. The equal sign ("=") appears in cells where the means of the corresponding treatment groups (column) showed no significant difference (at the 0.05 confidence level) for that measure (row). For cells where significant differences were found, the group with the higher (always "better") mean is indicated with an abbreviation followed by the "^" symbol(e.g. " $\mathrm{M}^{\wedge}$ " indicates a higher/better mean for males.) Some cells are shaded to highlight matches across columns for a given measure. The experimental measures (rows) include teammate desirability, the nine personality dimensions relevant to the task scenario as previously identified by Venkatsubramanyan and Hill (2007) and two additional measures: 1) Rating Confidence which captures the degree of confidence subjects felt in their decision and 2) the binary Yes/No decision to include the potential teammate represented by the ePersona, in the fictitious project team.

Table 1 relates to Proposition 1 which posited that both males (1a) and females (1b) would perceive target ePersonas including social networking presence more positively than those without. The proposition was based on relevant literature and the research model and indeed, the results support this expectation. Both female and male perceivers showed a preference for ePersonas with social networking presence across several dimensions.

Though there was some overlap between females and males in the specific dimensions affected, there were even more dimensions where the two genders differed. Both male and female perceivers gave advantage to social networking personas in judging the Work with People and Curious dimensions. But females treated ePersonas similarly across four (4) additional dimensions (Desirability, Manage Multiple Tasks, Handle Conflict and Adapt to New Situations) while males did so for only one (1), Manage Anger, which was apparently not salient for females. And so males registered significant advantage for social networkers across only three (3) dimensions, as opposed to six (6) for females, and yet, only the males showed significance in the Yes/No decision outcome measure, one that ostensibly reflects a comprehensive summation of desirability and the nine dimensions. This might be interpreted plausibly as males feeling more freedom to be decisive, even without delving as deeply and finding as much convincing evidence as the females, due to males' confidence that they will have the power to control the outcome and diffuse any consequences that would possibly derive.

In any case, the overarching implication of Table 1 is that social networking presence does make a difference, for perceivers of both genders, but in subtly different ways and to differing degrees. Looking deeper, the next set of propositions explores how the target gender plays a role within the context of social networking presence or lack thereof for female perceivers $(\mathrm{P} 2 \mathrm{a} / \mathrm{b})$.

Table 2, providing significance findings for female perceivers only, suggests a number of interesting observations with respect to Propositions $2 \mathrm{a}$ and $2 \mathrm{~b}$, that females will perceive females more positively than males for targets without or with social networking presence. The leftmost two columns of results correspond to $\mathrm{P} 2 \mathrm{a}$ and $\mathrm{b}$, respectively, and show no support for either. No significant differences were found in comparing female to male targets without social networking presence (P2a). For ePersonas with social networking presence (P2b), significance was found only for a single dimension, Effective Team Member, and male targets were rated 
Table 1. Comparison of social networking influence for female vs. male perceivers

\begin{tabular}{|c|c|c|}
\hline & $\begin{array}{c}\text { Female Perceivers } \\
\text { (results group both F \& M targets) }\end{array}$ & $\begin{array}{c}\text { Male Perceivers } \\
\text { (results group both F \& M targets) }\end{array}$ \\
\hline Impression Dimensions & SN vs. no SN & SN vs. no SN \\
\hline Desirability & $\mathrm{SN}^{\wedge}$ & $=$ \\
\hline Effective Team Member & $=$ & $=$ \\
\hline Excellence & $=$ & $=$ \\
\hline Manage Multiple Tasks & $\mathrm{SN}^{\wedge}$ & $=$ \\
\hline Work with People & $\mathrm{SN}^{\wedge}$ & $\mathrm{SN}^{\wedge}$ \\
\hline Handle Conflict & $\mathrm{SN}^{\wedge}$ & $=$ \\
\hline Manage Anger & $=$ & $\mathrm{SN}^{\wedge}$ \\
\hline Curious & $\mathrm{SN}^{\wedge}$ & $\mathrm{SN}^{\wedge}$ \\
\hline Adapt to New Situations & $\mathrm{SN}^{\wedge}$ & $=$ \\
\hline Ability to Take Direction & $=$ & $=$ \\
\hline \multicolumn{3}{|l|}{ Additional Measures } \\
\hline Rating Confidence & $=$ & $=$ \\
\hline Yes/No Decision & $=$ & $\mathrm{SN}^{\wedge}$ \\
\hline
\end{tabular}

(where "=" indicates no significant difference at .05 level; $\mathrm{SN}^{\wedge}=$ Social Networking higher at .05)

(Note: $\mathrm{n}=104$ Males +106 Females $=210$ perceivers total; $\mathrm{F} \& \mathrm{M}=$ Female $\&$ Male targets)

Table 2. Significance for female perceivers

\begin{tabular}{|c|c|c|c|c|}
\hline \multirow[b]{3}{*}{ Impression Dimensions } & \multicolumn{4}{|c|}{ Target Characteristics } \\
\hline & \multicolumn{2}{|c|}{$\begin{array}{l}\text { Gender advantage effect } \\
\text { within No } \mathrm{SN} \text { and } \mathrm{SN} \text { target groups }\end{array}$} & \multicolumn{2}{|c|}{$\begin{array}{c}\text { SN advantage effect } \\
\text { within } F \text { and } M \text { target groups }\end{array}$} \\
\hline & No SN: F vs. M & SN: F vs. M & F: SN vs. no SN & M: SN vs. no SN \\
\hline Desirability & $=$ & $=$ & $=$ & $\mathrm{SN}^{\wedge}$ \\
\hline Effective Team Member & $=$ & $M^{\wedge}$ & $=$ & $\mathrm{SN}^{\wedge}$ \\
\hline Excellence & $=$ & $=$ & $=$ & $\mathrm{SN}^{\wedge}$ \\
\hline Manage Multiple Tasks & $=$ & $=$ & $=$ & $\mathrm{SN}^{\wedge}$ \\
\hline Work with People & $=$ & $=$ & $\mathrm{SN}^{\wedge}$ & $\mathrm{SN}^{\wedge}$ \\
\hline Handle Conflict & $=$ & $=$ & $=$ & $=$ \\
\hline Manage Anger & $=$ & $=$ & $=$ & $=$ \\
\hline Curious & $=$ & $=$ & $\mathrm{SN}^{\wedge}$ & $\mathrm{SN}^{\wedge}$ \\
\hline Adapt to New Situations & $=$ & $=$ & $\mathrm{SN}^{\wedge}$ & $\mathrm{SN}^{\wedge}$ \\
\hline Ability to Take Direction & $=$ & $=$ & $=$ & $=$ \\
\hline \multicolumn{5}{|l|}{ Additional Measures } \\
\hline Rating Confidence & $=$ & $=$ & $=$ & $=$ \\
\hline Yes/No Decision & $=$ & $=$ & $=$ & $=$ \\
\hline
\end{tabular}

(where "=" indicates no significant difference at .05 level; $\mathrm{SN}^{\wedge}=$ Social Networking higher; $\mathrm{M}^{\wedge}=$ Males higher) (Note: $\mathrm{n}=106$ Females; $\mathrm{SN}=$ Social Networking; $\mathrm{F}=$ Female; $\mathrm{M}=$ Male) 
higher, not lower, as predicted in the proposition. This may owe to the overriding influence of established stereotypes when other cueing is indiscriminate as it was in this treatment with all targets showing social networking presence equally (target gender was the only variable).

But the result is intriguing in that it surfaced only in the social networking presence treatment (P2b) and not in the treatment that was identical except for the absence of social networking presence (P2a). The logical implication is an interaction effect-these female perceivers viewed male targets differently from female targets in the context of social networking presence only, at least on this single dimension-target gender and social networking presence effect differently when both are present than in the case of either alone. This is consistent with the observation from Table 1 that male and female perceivers view the value of social networking presence differently, but it adds a nuance-that those differences may further vary, depending on target gender, as suggested by Propositions P3a and P3b. To delve further into the interaction implications, the analysis explored how females viewed the added value of social networking for female as opposed to male targets (P3a), as seen in the rightmost two columns above.

The most notable point that surfaces is that female perceivers' impressions were affected by social networking across more dimensions for male targets than for female targets. Significant effects from social networking were found only for three (3) of the ten dimensions for female targets (Work with People, Curious, and Adapt to New Situations). And the same three (3) dimensions showed significant effects for male targets but four (4) additional dimensions also show significant impact from social networking for the males, for a total of seven (7) affected among the ten (10) measured.

For male targets, these female perceivers' impressions of the Desirability, Effective Team Member, Excellence and Manage Multiple Task dimensions showed significant positive effect from social networking that was not found in their perceptions of female targets where the sole difference was gender. This implies an interaction effect-the presence of social networking affects females' perception differently, and more comprehensively for the males they are evaluating than the females. In other words, female perceivers give a greater social networking premium to males than females and/or penalize males more than females for the lack of social networking presence. Indeed closer inspection of the data suggests that it is a combination of both as the specific means for at least five (5) of the dimensions show a pattern of wider spread for the male targets-those with social networking outscore the social networking females while those without score lower than their female counterparts.

Thus, Table 2 provides convincing support for P3a and the existence of an interaction effect, for female perceivers, between target gender and social networking presence. In this case, the female perceivers are clearly more affected by social networking presence in male ePersonas than in female ePersonas. Specifically the findings suggest that, for female perceivers, the stereotypical view of males as less socially adroit than females is strongly reinforced when male targets lack social networking presence and this effect is excessively negative with respect to the non-social networking female targets. Interestingly, the positive effect of social networking presence on female perceivers' impressions of male targets is so exaggerated that this same stereotype is strongly negated for male targets engaged in social networking, perhaps because the elevated social investment is unexpected for males and defies the stereotypical view held by the females, even when compared to social networking females.

The obvious next question is whether the same phenomenon holds for male perceivers as examined in Table 3.

Table 3 replicates Table 2 but for male perceivers and is interesting for similar reasons and by contrast with Table 2's results for female perceivers.

First, as with female perceivers, the leftmost two columns of Table 3 show that there is no support for the propositions that males 
Table 3. Significance for male perceivers

\begin{tabular}{|c|c|c|c|c|}
\hline & \multicolumn{4}{|c|}{ Target Characteristics } \\
\hline & \multicolumn{2}{|c|}{$\begin{array}{c}\text { Gender advantage effect } \\
\text { within No SN and SN target groups }\end{array}$} & \multicolumn{2}{c|}{$\begin{array}{c}\text { SN advantage effect } \\
\text { within F and M target groups }\end{array}$} \\
\hline Impression Dimensions & No SN: F vs. M & SN: F vs. M & F: SN vs. no SN & M: SN vs. no SN \\
\hline Desirability & $=$ & $=$ & $=$ & $=$ \\
\hline Effective Team Member & $=$ & $=$ & $=$ & $=$ \\
\hline Excellence & $=$ & $=$ & $\mathrm{SN}^{\wedge}$ & $=$ \\
\hline Manage Multiple Tasks & $=$ & $=$ & $\mathrm{SN}^{\wedge}$ & $\mathrm{SN}^{\wedge}$ \\
\hline Work with People & $=$ & $=$ & $=$ & $=$ \\
\hline Handle Conflict & $=$ & $=$ & $=$ & $\mathrm{SN}^{\wedge}$ \\
\hline Manage Anger & $=$ & $=$ & $=$ & $=$ \\
\hline Curious & $=$ & $=$ & $=$ & $=$ \\
\hline Adapt to New Situations & $=$ & $=$ & $=$ & $=$ \\
\hline Ability to Take Direction & $=$ & $=$ & $=$ & $=$ \\
\hline Additional Measures & $=$ & $=$ & $=$ & $=$ \\
\hline Rating Confidence & $=$ & $=$ & $=$ & $=$ \\
\hline Yes/No Decision & $=$ & $=$ & $=$ & $=$ \\
\hline
\end{tabular}

(where "=" indicates no significant difference at .05 level; $\mathrm{SN}^{\wedge}=$ Social Networking higher)

(Note: $\mathrm{n}=104$ Males; $\mathrm{SN}=$ Social Networking; $\mathrm{F}=$ Female; $\mathrm{M}=$ Male)

would show a target gender preference when ePersonas lack or include social networking presence $(\mathrm{P} 2 \mathrm{c}$ and $\mathrm{P} 2 \mathrm{~d}$, respectively). In contrast to the results for female perceivers however, there is no stereotypical effect that gives the contrasting gender, female, an advantage in any dimension whether social networking presence is apparent or not.

In further similarity to female perceivers, male perceivers show some interaction effect between target gender and social networking presence so $\mathrm{P} 3 \mathrm{~b}$ is somewhat supported but this is far less pronounced than in the case of female perceivers. For most of the ten (10) dimensions, there is no significant difference in their perceptions of either males or females, based on social networking presence. For one (1) of the ten dimensions, Work with People, significance is found both for male and female targets, so male perceivers are consistent across target gender on this dimension (as are females according to Table 2).
For these male perceivers, then, the only target gender differences due to social networking presence are found in Manage Multiple Tasks (advantage only for female targets), Manage Anger (advantage only for male targets), and Curious (advantage only for female targets). A difference is also found however, with advantage for males only, in the additional experimental binary measure, the Yes/No decision, referring to the scenario task of choosing a teammate. Again, as with the similar result from Table 1, the implication is that male perceivers are more comfortable than female perceivers, making the choice decision based on less evidence, possibly due to greater confidence in their power to control the eventual consequences.

In summary, Table 3 suggests that for males, as for females, there is some interaction between target gender and social networking presence. The effect is different however, from that for female perceivers in that it is not as consistent or 
as comprehensive across the range of impression dimensions. And yet, for male perceivers, it is seen in the Yes/No measure which intuitively would seem to encapsulate the range of dimensions in being the action outcome.

Table 4, comparing the significance findings from Tables 2 and 3, helps summarize and also highlights interesting contrasts.

Only for the Work with People dimension do male and female perceivers give social networking advantage to both male and female targets alike, though they both are consistent across target genders with respect to showing no significant social networking effect for three (3) other dimensions: Handle Conflict, Adapt to New Situations and Ability to Take Direction. Both also give social networking advantage to females for Curious, but only female perceivers do so for male targets. Thus, we see again that there is some overlap and some difference in how male and female perceivers are impressed by social networking, depending target gender. Target gender changes the way they both view social networking in ePersonas but in different ways and to different degrees. Perhaps the most interesting inconsistency is that, for the Manage Multiple Tasks dimension, male perceivers give a social networking advantage only to female targets while the reverse is true-female perceivers give it only to male targets.

\section{CONCLUSION}

The data lend support to some of the propositions and suggest some interesting nuances in the similarities and differences between male and female perceivers and the way their ePerception is affected by target gender, social networking presence, and interactions between the two. Previous research identifying the effects of social networking presence and perceiver gender were further substantiated and extended to incorporate ePersona gender and the analysis surfaced intriguing phenomena.

Specifically this study found that both males and females tend to perceive a potential teammate with social networking activity more favorably than one without. However, results also indicate that males and females perceive and assign that social networking benefit differently. Female perceivers in our study viewed those engaged in social networking sites as more curious and desirable and more capable of multi-tasking, handling conflict, adapting to new situations and interacting well with others than those with no involvement in social networks. Meanwhile, male perceivers viewed social networking activity as an indication that a potential teammate is more curious, better able to manage anger and more likely to work well with others. These findings offer support for Proposition $1 \mathrm{~b}$ and some support for Proposition 1a.

Our findings also suggest that social networking activity is a more influential factor than is target gender as neither male nor female perceivers significantly preferred one gender over the other when controlling for targets' involvement in social networks. Therefore we find no support for Propositions 2a-2d.

There does appear however, to be an interaction effect between target gender and social networking presence. Female perceivers showed a preference for male targets with social networking presence over males without social networking presence on seven of the ten assessed characteristics and a preference for social networking females on three of the target characteristics. Of particular interest is that female perceivers appear to assign a greater value to the social networking activities of male targets than that of female targets and assign a greater penalty to non-social networking males than they do to non-social networking females. This finding supports Proposition $3 a$.

Male perceivers also had more favorable impressions of those with social networking activity, scoring social networking males more favorably than non-social networking males on three characteristics and scoring social networking females higher than non-social networking females on three characteristics. Thus there does appear to be some support for Proposition $3 \mathrm{~b}$ however the interaction effect of target gender 
Table 4. Significance comparison between male \& female perceivers

\begin{tabular}{|c|c|c|c|c|}
\hline \multirow[b]{3}{*}{ Impression Dimensions } & \multicolumn{4}{|c|}{ Target Characteristics } \\
\hline & \multicolumn{2}{|c|}{$\begin{array}{c}\text { Gender advantage effect } \\
\text { within No SN and SN target groups }\end{array}$} & \multicolumn{2}{|c|}{$\begin{array}{c}\text { SN advantage effect } \\
\text { within } F \text { and } M \text { target groups }\end{array}$} \\
\hline & No SN: F vs. M & SN: F vs. M & F: SN vs. no SN & M: SN vs. no SN \\
\hline Desirability & $=$ & $=$ & $=$ & $\mathrm{SN}^{\wedge}$ by $\mathrm{F}$ only \\
\hline Effective Team Member & $=$ & $\mathrm{M}^{\wedge}$ by $\mathrm{F}$ only & $=$ & $\mathrm{SN}^{\wedge}$ by $\mathrm{F}$ only \\
\hline Excellence & $=$ & $=$ & $=$ & $\mathrm{SN}^{\wedge}$ by $\mathrm{F}$ only \\
\hline Manage Multiple Tasks & $=$ & $=$ & \multicolumn{2}{|c|}{$\begin{array}{l}\mathrm{SN}^{\wedge} \text { for } \mathrm{F} \text { by } \mathrm{M} \text { (but not by } \mathrm{F} \text { ) } \\
\text { and } \\
\mathrm{SN}^{\wedge} \text { for } \mathrm{M} \text { by } \mathrm{F} \text { (but not by } \mathrm{M} \text { ) }\end{array}$} \\
\hline Work with People & $=$ & $=$ & $\begin{array}{l}\mathrm{SN}^{\wedge} \text { by both } \\
\mathrm{M} \& \mathrm{~F}\end{array}$ & $\mathrm{SN}^{\wedge}$ by both $\mathrm{M} \& \mathrm{~F}$ \\
\hline Handle Conflict & $=$ & $=$ & $=$ & $=$ \\
\hline Manage Anger & $=$ & $=$ & $=$ & $\mathrm{SN}^{\wedge}$ by $\mathrm{M}$ only \\
\hline Curious & $=$ & $=$ & $\begin{array}{l}\mathrm{SN}^{\wedge} \text { by both } \\
\mathrm{M} \& \mathrm{~F}\end{array}$ & $\mathrm{SN}^{\wedge}$ by $\mathrm{F}$ only \\
\hline Adapt to New Situations & $=$ & $=$ & $=$ & $=$ \\
\hline Ability to Take Direction & $=$ & $=$ & $=$ & $=$ \\
\hline \multicolumn{5}{|l|}{ Additional Measures } \\
\hline Rating Confidence & $=$ & $=$ & $=$ & $=$ \\
\hline Yes/No Decision & $=$ & $=$ & $=$ & $\mathrm{SN}^{\wedge}$ by $\mathrm{M}$ only \\
\hline
\end{tabular}

(where "=" indicates no significant difference at .05 level; $\mathrm{SN}^{\wedge}=$ Social Networking higher; $\mathrm{M}^{\wedge}=$ Males higher) (Note: $\mathrm{n}=104$ Males/106 females; $\mathrm{SN}=$ Social Networking; $\mathrm{F}=$ Female; $\mathrm{M}=$ Male)

and social networking activity is not as strong for male perceivers as it is for female perceivers.

These findings hold implications for practice, pedagogy and further research. For managers, the observed interaction for perceivers of both genders (especially females) between social networking presence and target gender (same as perceiver or different) amounts to a bias that may distort impressions of job applicants, for example, and could lead to sub-optimal hiring decision outcomes in the workplace. In particular, hiring supervisors should recognize the benefits and penalties a female interviewer may place upon male applicants based solely upon their social networking activities. Although the student-based subject pool admittedly limits the degree of generalizability to professional environments, one can argue that these individuals are no more than a year or two away from entering the workforce and they may be expected to carry their biases with them into positions where they will evaluate potential job applicants for their work teams. It thus behooves them, and their future managers, to develop an awareness of their biases with the aim of minimizing them and/or compensating for them in their decisions. And it behooves job applicants to be aware of them, particularly the strong negative reactions to the lack of social networking presence, but also the sensitivity to excessively high levels of such activity, as evidenced in the qualitative responses, and to consider tuning their ePersonas accordingly, to the extent possible, when job seeking. 
Findings concerning individuals' use and valuation of social networking activity in impression formation hold implications for instructors as well. This study suggests that Web-based information may well play a role in students' selection of teammates for class-based team projects be they face-to-face teams in traditional classrooms or virtual teams in online courses. The availability of such influential information on the Internet may be particularly problematic for instructors looking to minimize students' preconceived opinions of potential teammates based upon factors such as social networking activity, which may play little or no role in the ability of a student to contribute meaningfully to a group. Although our sample was limited to business students, our findings may apply to other student groups as well given that most Millennials (a term often used to label those born roughly between 1980 and 2000) are technically savvy and it is arguable that no one group within this generation is any more or less likely to turn to the Internet for information when making such selection decisions.

While this and similar studies have shed some light upon the impacts of social networking activity on our perceptions of others, many questions regarding the role of Web-based information in impression formation remain unanswered. Focusing specifically on social networking, some extensions of this study would entail exploring the question of how much social networking presence is beneficial (or detrimental), the consequences of possessing a common name or sharing a name with a celebrity (making it hard to disambiguate the right identity), and the role of perceiver characteristics beyond gender on the impressions formed. Future research could also investigate the same research questions posed by our study to determine if the findings indeed apply to other populations such as professionals, non-business majors, and non-Milliennials.

Our understanding of ePerception would be further extended by studies that look beyond social networking activity to other forms of Web presence and the role they play in impression formation and by investigating factors influencing the search process itself (ex. searchability, filters, etc.). Further, the types of personality traits considered by different categories of perceivers during Web-based searches and how these traits of interest may vary by decision making context also warrant investigation. As ePerception becomes ever more pervasive, such research, though lagging the technology itself, will help develop our understanding toward better decisions and more control of over our identities in the digital future.

\section{ACKNOWLEDGMENT}

We thank the reviewers and editors for their insights and assistance with this manuscript. This research was supported by the Behavioral Research Group of the College of Business at San Jose State University.

\section{REFERENCES}

Back, M. D., Stopfer, J. M., Vazire, S., Gaddis, S., Schmukle, S. C., Egloff, B., et al. (2010). Facebook profiles reflect actual personality not self-idealization. Psychological Science. Retrieved from http://pss.sagepub.com/content/ early/2010/01/28/0956797609360756.extract

Brewer, M. B. (1988). A dual process model of impression formation. In Scull, J. R. K., \& Wyer, R. S. (Eds.), Advances in social cognition (Vol. 1, pp. 1-36). Mahwah, NJ: Lawrence Erlbaum.

CareerBuilder. (2008). One-in-five employers use social networking sites to screen job candidates. Retrieved from http://www.careerbuilder.com/ share/aboutus/pressreleasesdetail.aspx $? i d=p r 459 \&$ $\mathrm{sd}=9 \% 2 \mathrm{~F} 10 \% 2 \mathrm{~F} 2008 \& \mathrm{ed}=12 \% 2 \mathrm{~F} 31 \% 2 \mathrm{~F} 2008 \& \mathrm{si}$ teid=cbpr\&sc_cmp1=cb_pr459_\&cbRecursionCnt $=1 \&$ cbsid $=894900 \mathrm{f} 6873 \mathrm{~d} 4775 \mathrm{af} 1 \mathrm{c} 4681201 \mathrm{~d} 0758$ 275320933-R5-4

Cross-tab Marketing Services. (2010). Online reputation in a connected world. Retrieved from http://search.microsoft.com/results.aspx?mkt=enUS\&setlang=en-US\&q=Online reputation in a connected world 
Ford, N., Miller, D., \& Moss, N. (2005). Web search strategies and human individual differences: A combined analysis. Journal of the American Society for Information Science and Technology, 56(7), 757-764. doi:10.1002/asi.20173

Gefen, D., \& Straub, D. W.(1997). Gender differences in the perception and use of e-mail: An extension to the technology acceptance model. Management Information Systems Quarterly, 21(4), 389-400. doi: $10.2307 / 249720$

Hancock, J. T., \& Dunham, P. J. (2001). Impression formation in computer-mediated communication revisited. Communication Research, 28(3), 325-347. doi:10.1177/009365001028003004

Huffaker, D. A., \& Calvert, S. L. (2005). Gender, identity, and language use in teenage blogs. Journal of Computer-Mediated Communication, 10(2).

Jacobson, D. (1999). Impression formation in cyberspace: Online expectations and offline experiences in text-based virtual communities. Journal of Computer-Mediated Communication, 5(1), 461-479.

Kalyanaraman, S., \& Sundar, S. S. (2008). Impression-formation effects in online mediated communication . In Konijn, E. A., Tanis, M., Utz, S., \& Linden, A. (Eds.), Mediated interpersonal communication (pp. 217-233). Mahwah, NJ: Lawrence Erlbaum.

Lea, M., \& Spears, R. (1991). Computer-mediated communication, de-individuation and group decision-making. International Journal of ManMachine Studies, 34(2), 283-301. doi:10.1016/00207373(91)90045-9

Lee, E. J. (2004). Effects of gendered character representation on person perception and informational social influence in computer-mediated communication. Computers in Human Behavior, 20(6), 779-799. doi:10.1016/j.chb.2003.11.005

Likert, R. (1932). A technique for the measurement of attitudes. Archives de Psychologie, 140, 1-55.

Markey, P. M., \& Wells, S. M. (2002). Interpersonal perception in internet chat rooms. Journal of Research in Personality, 36, 134-146. doi:10.1006/ jrpe.2002.2340

McKenna, K. Y. A., \& Bargh, J. (2000). Plan 9 from cyberspace: The implications of the internet for personality and social psychology. Personality and Social Psychology Review, 4(1), 57-75. doi:10.1207/ S15327957PSPR0401 6
Nass, C., Moon, Y., \& Green, N. (1997). Are machines gender neutral? Gender-stereotypic responses to computers with voices. Journal of Applied Social Psychology, 27(10), 864-876. doi:10.1111/j.1559-1816.1997.tb00275.x

Postmes, T., \& Spears, R. (2002). Behavior online: Does anonymous computer communication reduce gender inequality? Personality and Social Psychology Bulletin, 28(8), 1073-1083. doi:10.1177/01461672022811006

Richardson, J., \& Swan, K. (2003). Examining social presence in online courses in relation to students' perceived learning and satisfaction. Journal of Asynchronous Learning Networks, 7(1), 68-88.

Sherman, J. W., Lee, A. Y., Bessenoff, G. R., \& Frost, L. A. (1998). Stereotype efficiency reconsidered: Encoding flexibility under cognitive load. Journal of Personality and Social Psychology, 75(3), 589-606. doi:10.1037/0022-3514.75.3.589

Vazire, S., \& Gosling, S. D. (2004). e-Perceptions: Personality impressions based on personal websites. Journal of Personality and Social Psychology, 87, 123-132. doi:10.1037/0022-3514.87.1.123

Venkatsubramanyan, S., \& Hill, T. (2009a). An empirical investigation into the effects of web search characteristics on decisions associated with impression formation. Information Systems Frontiers, 12(5), 579-593. doi:10.1007/s10796-009-9177-9

Venkatsubramanyan, S., \& Hill, T. (2009b). Gender differences in social networking presence effects on web-based impression formation. In Proceedings of the Americas Conference on Information Systems.

Venkatsubramanyan, S., \& Hill, T. R. (2007, December). Evaluating potential team members using search results: An experimental study. Paper presented at the International Symposium on Information Systems, Hyderabad, India.

Walther, J. B. (1997). Group and interpersonal effects in international computer-mediated collaboration. Communication Research, 23, 342-369. doi:10.1111/j.1468-2958.1997.tb00400.x

Walther, J. B., \& Parks, M. R. (2002). Cues filtered out, cues filtered in: Computer-mediated communication and relationships . In Knapp, M. L., \& Daly, J. A.(Eds.), Handbook of interpersonal communication (3rd ed., pp. 529-563). Thousand Oaks, CA: Sage. 
Walther, J. B., Van Der Heide, B., Hamel, L. M., \& Shulman, H. C. (2009). Self-generated versus othergenerated statements and impressions in computermediated communication: A test of warranting theory using Facebook. Communication Research, 36(2), 229-253. doi:10.1177/0093650208330251

Walther, J. B., Van Der Heide, B., Kim, S.-Y., Westerman, D., \& Tong, S. T. (2008). The role of friends' appearance and behavior on evaluations of individuals on Facebook: Are we known by the company we keep? Human Communication Research, 34(1), 28-49.
Widmeyer, W. N., \& Loy, J. W. (1988). When you're hot, you're hot! Warm-cold effects in first impressions of persons and teaching effectiveness. Journal of Educational Psychology, 80, 118-121.

Leslie Jordan Albert is an Assistant Professor in the Management Information Systems department in the College of Business at San Jose State University. She received her Ph.D. in MIS from the University of Oklahoma. Her research interests include computer-mediated communication, gender differences in IS, social networks, online learning, and the ability of technology to enhance individual creativity. Her work has been published in Information Systems Journal and in numerous conference proceedings.

Timothy R. Hill is the chair of the Management Information Systems department and a Linda F. Morasch Fellow for Innovative e-Learning in the College of Business at San Jose State University. He has published research on innovative applications of emerging technologies, spanning artificial intelligence, neural networks, graphic visualization and manipulation, and more recently, mobile, multi-layered, media-rich e-learning environments and Web-related phenomena involving social perception, identity and content aging. He continues to experiment in e-Learning with a variety of techniques, technologies and pedagogies.

Shailaja Venkatsubramanyan is an Associate Professor in the Management Information Systems department in the College of Business at San Jose State University. She has a Ph.D. in MIS from the University of Arizona and has worked at Price Waterhouse, Tulane University, and Kanisa (a Knowledge Management startup in the Silicon Valley). Her research interests include knowledge management, information retrieval, search engine valuation, web log analysis, digital personas, and aging content on the Internet. She is also involved in studies involving the use of cloud computing to streamline operations in developing countries. 


\section{APPENDIX A.}

Figure 2. Search results for Jane Doe 1

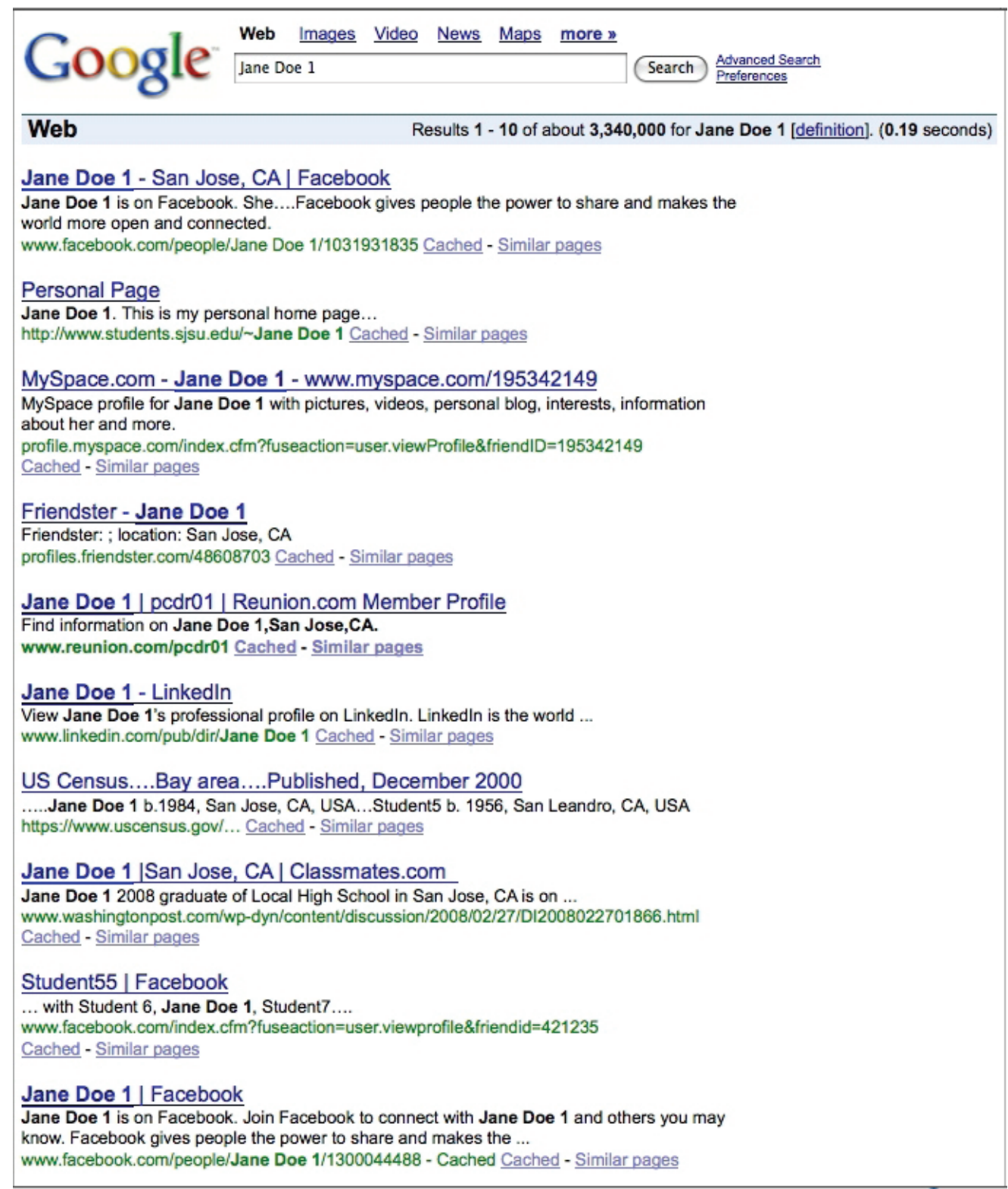




\section{APPENDIX B.}

Figure 3. Search results for Jane Doe 2

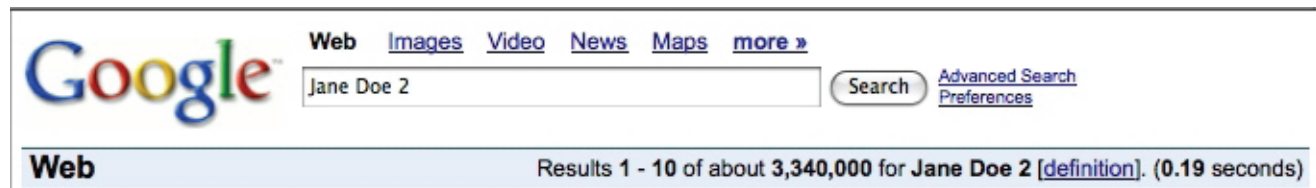

People Search Directory - Find People Jane Doe 2...

Jane Doe 247 Beaumont, Santa Clara County, CA. She...

www.directory.com/people-search-directory/L3/6264 Cached - Similar pages

\section{Jane Doe 2: WhitePages.com}

Find Jane Doe 2. Maps of all Jane Doe 2s

www.classmates.com/directory/school/... - 504k - Cached - Similar pages - Note this

$\underline{\text { Cached }- \text { Similar pages }}$

\section{Birth Records - Santa Clara County, CA - BIRTH 1988...}

... Student8 born 04-Nov-1988, Jane Doe 2556 born -05-June-1988, Jane Doe 24345 born 5-January-1988, Jane Doe 2...

ftp.rootsweb.com/pub/usgenweb/tx/tarrant/vitals/births/1988/tarrv88g.txt

Cached - Similar pages

\section{Personal Page}

Jane Doe 2. This is my personal home page...

http://www.students.sjsu.edu/ Jane Doe 2 Cached - Similar pages

\section{People Search Directory - Find People Jane Doe 2...}

Jane Doe 247 Beaumont, Santa Clara County, CA

www.directory.com/people-search-directory/L3/6264 Cached - Similar pages

\section{Jane Doe 2 - Genealogy - Geni}

View Jane Doe 2's genealogy on Geni, a free resource with over 70 million profiles of ancestors and living relatives. Page updated Oct 3, 2009

www.geni.com/people/Jane Doe 2 2.../6000000006295163214 Cached - Similar pages

\section{Jane Doe 2: WhitePages.com}

Find Jane Doe 2. Popularity and maps of all Jane Doe 2s.

names. whitepages.com/Jane Doe 2 Cached - Similar pages

Jane Doe 2- Email, Address, Phone number, everything ...

Everything you need to know about Jane Doe 2Email addresses, Phone numbers, Biography, Address history, ...

www. 123people.com/s/Jane+doe Cached - Similar pages

US Census....Bay area....Published, December 2000

.....Jane Doe 2 b.1984, San Jose, CA, USA...Student5 b. 1956, San Leandro, CA, USA

https $/ /$ www. uscensus.gov $\ldots$ Cached - Similar pages

discuss@menelaus: [4510] in IMAP Delivery

Council=20 rosser fronza Jane Doe 2 sheile harrellc alvin curry.Weber ilary blasi imogen bailey, ...

diswww.mit.edu/menelaus/imapdel/4510 $\underline{\text { Cached }}$ - $\underline{\text { Similar pages }}$ 


\title{
CALL FOR ARTICLES
}

\section{International Journal of E-Politics}

\author{
An official publication of the Information Resources Management Association
}

The Editor-in-Chief of the International Journal of E-Politcs (IJEP) would like to invite you to consider submitting a manuscript for inclusion in this scholarly journal.

\section{Mission:}

The mission of the International Journal of E-Politcs (IJEP) is to define and expand the boundaries of e-politics as an emerging area of inter-disciplinary research and practice by assisting in the development of e-politics theories and empirical models. The journal creates a venue for empirical, theoretical, and practical scholarly work on e-politics to be published, leading to sharing of ideas between practitioners and academics in this field. IJEP contributes to the creation of a community of e-politics researchers by serving as a "hub" for related activities, such as organizing seminars and conferences on epolitics and publication of books on e-politics.

TOPICS OF INTEREST INCLUDE BUT ARE NOT LIMITED TO:

- E-voting and electronically enabled e-government

- Impact of globalization on the political role played by the IT unit within organizations

- Impact of race and gender on electronically enabled political manipulations

- Party politics and social activism

- Politics of diffusion of change within organizations

- Politics of social networking communities, including: learning communities, customers' communities, e-dating communities, gaming communities, support group communities, etc.

- Politics of the IT function and role in organizations

- Politics of virtual communities and social networking communities

- Politics of geographically based virtual communities

- Use of electronic media for surveillance manipulation and harassment

- Use of electronic media in industrial and labor relations

- Utilization of electronic media for governance and politicking at the municipal, state, national, and international levels

- Utilization of electronic media for political debate, information sharing, political decision making, and fundraising

All submissions should be e-mailed to: Celia Romm Livermore, Editor-in-Chief ak1667@wayne.edu

Ideas for Special Theme Issues may be submitted to the Editor-in-Chief.

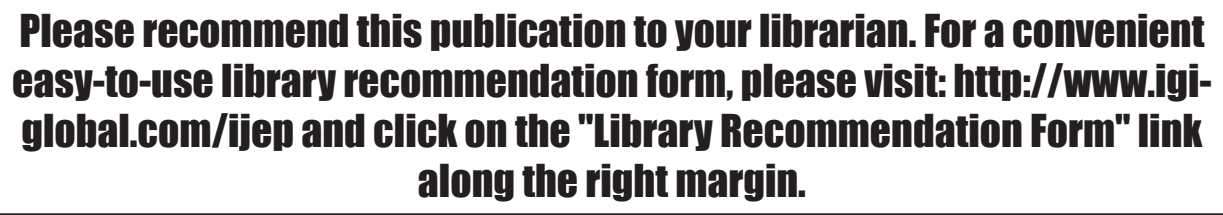

